\title{
Pharmacy Apps: a new frontier on the digital landscape?
}

Michael J. DAVIES, Matthew COLLINGS, William FLETCHER, Hassan MUJTABA.

Received (first version): 20 -Apr-2014

Accepted: 21-Aug-2014

\section{ABSTRACT}

Background: Over the course of recent years smartphone and tablet technology has evolved rapidly. Similarly, the sphere of healthcare is constantly developing and striving to embrace the newest forms of technology in order to optimise function. Many opportunities for mobile applications (i.e. 'apps') pertinent to the healthcare sector are now emerging.

Objective: This study will consider whether registered pharmacists within the United Kingdom (UK) believe it appropriate to use mobile apps during the provision of healthcare within the community setting.

Methods: Further to Liverpool John Moores University (LJMU) ethical approval, the 30 item questionnaire was distributed to UK registered pharmacists $(n=600)$ practising within inner city Manchester, Liverpool and Newcastle. The questions were formatted as multiple choice, Likert scales or the open answer type. On questionnaire completion and return, data were analysed using simple frequencies, cross tabulations and nonparametric techniques in the Statistical Package for the Social Sciences (SPSS) (v18)

Results: The majority of respondents $(78.4 \%$ of 211 participants) confirmed that they were confident when using mobile apps on their technology platform. In general, mobile apps were perceived to be useful in facilitating patient consultations $(55 \%)$ and supporting healthcare education $(80 \%)$. The main barrier for mobile app use within the workplace was company policy, deemed significant in the case of regional / national chain pharmacies $(p<0.001)$. Pharmacists alluded to the fact that whilst mobile apps demonstrate potential in modern day practise, they will have a greater impact in the future $(p<0.001)$.

Conclusion: The data indicate that although pharmacists are supportive of mobile apps in healthcare, a number of factors (i.e. risk, company policy and lack of regulation) may preclude their use in modern day pharmacy practise. Clearly, limitations of the technology must be addressed in order to maximise uptake within healthcare systems. Pharmacists suggest that as the younger generation ages, mobile apps will become a more accepted method by which to manage healthcare in the wider population

Keywords: Cellular Phone; Computers, Handheld; Pharmacists; Professional Practice; United Kingdom

Michael J. DAVIES. The School of Pharmacy and Biomolecular Sciences, Liverpool John Moores University (LJMU), Liverpool (United Kingdom).

m.davies1@ljmu.ac.uk

Matthew COLLINGS. The School of Pharmacy and

Biomolecular Sciences, Liverpool John Moores University (LJMU), Liverpool (United Kingdom).

William FLETCHER. The School of Pharmacy and Biomolecular Sciences, Liverpool John Moores University (LJMU), Liverpool (United Kingdom).

Hassan MUJTABA. The School of Pharmacy and

Biomolecular Sciences, Liverpool John Moores University (LJMU), Liverpool (United Kingdom).

\section{INTRODUCTION}

Healthcare is constantly evolving. Modern technologies offer scope for more effective ways to manage disease. Over the course of the last two decades, the Internet has transformed the way in which information is accessed. Mobile devices (i.e. smartphone and tablet platforms) took this a step further by allowing users to have remote access to the World Wide Web at their fingertips. Such devices now outnumber personal computers and will soon become the most common way to access data. ${ }^{1}$ Interest generated in this technology may be ascribed to the availability of over one and a half million applications, or 'apps', available for download. ${ }^{2}$ Apps may be described as software packages that are used to enhance the efficiency of a device or to add functionality. Mobile apps can provide the healthcare professional with opportunity for a quick, user-friendly way of accessing important medical information to support patient care. ${ }^{3}$

\section{Mobile Applications for Community Pharmacy}

The introduction of the New Pharmacy Contract in 2005 led to a dramatic change in the role of the community pharmacist. ${ }^{4}$ In brief, pharmacists must now execute a number of essential (i.e. prescription dispensing), advanced (i.e. 'medicines use reviews' (MURs) and 'new medicines service' (NMS)) and enhanced (i.e. smoking cessation) services that naturally place extra pressure on their daily routine. Clearly, finding the most efficient way of carrying out healthcare related tasks has never been so important.

The availability of apps on portable devices may lead to a reduction in the time taken to carry out a particular service or task; this being a key benefit to the pharmacist. To be a useful healthcare tool, a mobile app should inform the decision making process, facilitate pharmacist / staff / patient education, act as a communication aid and provide support to the patient within the community setting. ${ }^{5}$

With respect to the practice of pharmacy, mobile apps may be viewed as preferable to hard copy reference material due to their simplicity, user friendliness and regular updates. Here, it is illustrative to consider the fact that a number of pharmaceutically relevant organisations have produced mobile apps alongside traditional hard copy versions; for instance, The Royal Pharmaceutical Society British National Formulary (BNF) app allows healthcare professionals to access the BNF wherever they may be. ${ }^{6}$ Additional examples include 'The Pharmacist Letter' and 'Medscape', which allow users to rapidly access relevant literature relating to a desired topic. 
Furthermore, in 2011 DeArment investigated the suitability of pharmacy staff nominated as 'Wellness Ambassadors' who were equipped with tablet devices and asked to assist customers in the selection of over-the-counter medicines and vitamins, allowing them to make informed choices based on individual needs. The use of such technology was well received by both staff and customers, it was found to bridge a gap between front of store operations and the pharmacy, which was reported as being deficient. ${ }^{7}$

Mobile platforms also lend themselves well to the management of chronic medical conditions such as diabetes (i.e. promoting safe insulin use and reducing the incidence of hypoglycaemia). ${ }^{8} \mathrm{~A}$ powerful feature common to all mobile devices is the capacity to connect to additional monitoring platforms via 'sensing technology'. In this regard, Cai and coworkers considered the potential for Bluetooth technology to connect a smartphone to a glucose sensor in 2012. ${ }^{9}$ This strategy allowed the patient to store details of their blood glucose levels on a mobile device and then upload the data to the Internet for observation by a monitoring centre. If blood glucose levels were to reach pre-set thresholds an alarm would be triggered to send the patient a text with support information and if necessary details of nearest emergency contacts. This is an excellent example of "advanced healthcare-monitoring".

The technology may also serve to support healthcare education. ${ }^{10}$ Education within the healthcare setting is extremely important as there are frequent developments concerning new products and information. Naturally, this topic is extremely broad and a full / detailed explanation is beyond the remit of this document. However, aspects of relevance to mobile app use include pharmacist continuing education, staff training along with patient education.

There is a fundamental expectation, from both regulatory bodies and the public, that all healthcare professionals hold an up-to-date knowledge-base in order to provide optimal healthcare. ${ }^{11}$ As part of current registration requirements, UK-based pharmacists are obliged to actively participate in continuing professional development (CPD). ${ }^{12}$ In brief, the strategy involves participation in learning activities and the collection of evidence with related reflection; the ultimate aim being to improve practice. $^{13}$ Although the process is of educational value, studies suggest that the pharmacist often feels little need to complete CPD and they only undertake the exercise because it is a requirement stipulated by their profession. ${ }^{14}$ Here, mobile apps may be beneficial as they could offer both a rapid and convenient way in which to access medical information and facilitate the associated recording of learning activities. ${ }^{14}$

Similarly, organisations providing pharmaceutical services are obliged to have training programmes in place and related assessment strategies to ensure healthcare staff provide safe and effective patient care. ${ }^{15}$ That is to say, there is an expectation that all employees hold a good working knowledge of the use and supply of medicines, including prescription and over the counter products. ${ }^{15}$ With respect to pharmacist prescribing, mobile apps may indeed be applied to aid the process within both the community and hospital sectors. For example, in 2014 Haffey and co-workers considered the usefulness of mobile apps in assisting with the prescribing process in a hospital environment for inexperienced prescribers. ${ }^{16}$ Here, the group probed the practicality of 306 mobile apps for use both within and outside of the clinical setting. Overall a wide range of apps were noted to be available for use and a number of these were deemed appropriate to enhance prescribing performance. However, several limitations to the technology were outlined within the study (i.e. clinical reliability), which will be discussed in further detail within this article. Mobile apps may therefore hold potential to help pharmacists in gathering, contextualising and applying information to provide an effective clinical service.

Moreover, in order to optimise treatment outcomes it is important that patients understand aspects relating to their medical condition(s) and associated management strategies (i.e. patients should be educated to a suitable level). Currently, several mobile apps are available for recommendation to educate the patient and include for example Cures A-Z, Wellnote and Diabetes UK Tracker. ${ }^{17}$ An interesting approach for patient education within the clinical setting is the use of digital video apps on mobile platforms. This particular route was investigated by Brock and Smith in 2007, where 51 individuals in an outpatient infectious disease clinic at an academic medical centre were asked questions immediately before, immediately after and 4-6 weeks after exposure to digital video on the assigned mobile platforms. ${ }^{18}$ Markers for investigation included patient understanding of their disease and treatment strategies along with adherence to medication. The group noted statistically significant improvements in patient understanding further to viewing the digital videos. Overall, it was concluded that the use of digital video on mobile platforms may be extremely useful to convey healthcare information and that the media was indeed patient friendly.

Furthermore, scope exists for mobile apps to be utilised during patient consultations (i.e. MURs and NMS) with the pharmacist. Here, mobile apps such as Medscape may be applied to educate the patient, enhance compliance and adherence. ${ }^{17}$ With respect to the latter point, Dayer and colleagues considered the possibility of using mobile apps to improve medication adherence. ${ }^{19}$ At the time, the group suggested that mobile apps offer a fresh route for patients to derive the maximum benefit from treatment regimens (i.e. by reminding the patient to follow the treatment plan). The principal finding from this particular research study was the fact that mobile apps do indeed hold great potential to support non-adherent patients. 


\section{Barriers to Mobile App Use in Community Pharmacy}

Although mobile apps appear to demonstrate promise in the field of healthcare, a number of issues surrounding the use of such technology exist. For instance, patient age may significantly hinder uptake. Should the patient belong to the 'older generation' it is unlikely, but not impossible, they would utilise the technology platforms due to lack of familiarity. Organisations may have in place company policies that preclude the widespread use of mobile devices in the working environment. ${ }^{20}$ Additionally, poor store network coverage can interfere with those apps that require an internet connection.

A further prohibitive point associated with such technology involves the aspects of reliability and accuracy of the software platforms. ${ }^{21}$ Healthcare professionals may indeed be disinclined to use mobile apps should they hold concerns regarding suitability of use, a fact that may be attributed to our increasingly litigious societies. Naturally, these are all valid concerns relating to the use of mobile apps in the modern day healthcare setting and are investigated in greater detail within this piece.

\section{Lead In}

Mobile technology is becoming ever more prominent within society and is now unavoidably filtering into the healthcare arena. To date, limited research has been conducted to establish opinions held by pharmacists towards the use of mobile apps in healthcare. ${ }^{22}$ As a consequence, we believe it to be both timely and appropriate to consider the views held by pharmacists towards the use of mobile apps within the community setting.

\section{METHODS}

\section{Questionnaire Preparation and Ethical Approval}

Prior to study execution, a thorough literature review was conducted in order to identify current opinion regarding the use of mobile apps within the community pharmacy setting. Upon inspection of the published material, it was evident that important themes included the level of confidence a pharmacist has when using a mobile app, whether mobile apps have a role in modern day community pharmacy, the suitability of using a mobile app when compared to a hard reference source, the appropriateness of using a mobile app during patient consultations and barriers that may prevent the use of mobile apps. To this end, typical questions for the participants included:

1. How confident do you feel in using mobile apps?

2. To what extent do you believe healthcare apps have a place in modern day community pharmacy?

3. How comfortable would you be in using a mobile app over a hard copy reference source?

4. Mobile apps offer scope to aid the pharmacist during patient consultations (i.e. MURs and NMS).

5. Which of the following, if any, would present as a barrier to using mobile apps in your pharmacy?
The questionnaire was prepared using a range of Likert statements based upon the recurrent themes. For instance, the Likert scales involved: 'To a great extent', 'To a moderate extent', 'To some extent', 'To a small extent' and 'To no extent'. In addition, opportunity was given for respondents to offer their views in 'free-text' boxes to enable the reasoning of key trends noted within the data. Further to completion of the questionnaire and support materials (i.e. cover letter and participant information sheet) ethical approval was sought and obtained by the Liverpool John Moores University (LJMU) ethics committee.

\section{Questionnaire Distribution}

During January 2013, a questionnaire pack was distributed to 600 community pharmacies located within inner city Liverpool, Manchester and Newcastle. The pack consisted of a 30 item questionnaire, a covering letter, a participant information leaflet along with an A5 freepost response envelope for document return and confirmation of consent. At all times the information remained confidential. The questionnaires were coded for tracking purposes. In an attempt to improve the response rate, follow up calls were made to those pharmacies who did not respond after two weeks of receiving the questionnaire; if necessary, the questionnaire completed over the telephone or another questionnaire pack dispatched if requested.

\section{Statistical Analysis}

The data were collated and entered into the SPSS v18 platform to allow appropriate analysis; all entries were validated via triple inspection. Initially, descriptive tools were employed to obtain simple frequencies and cross-tabulations for the more basic type of question (i.e. How confident do you feel in using mobile apps?). Non-parametric techniques were utilised in the data analysis as these do not require a normal distribution in the identification of underlying trends. Here, cross referencing between demographic questions and opinions (i.e. those enquiries containing Likert scales) included the Mann-Whitney test along with the Kruskal-Wallis test and the $p$ values were then recorded; where a p-value of less than or equal to 0.05 was deemed to be of statistical significance.

\section{RESULTS}

\section{Pharmacist Demographics}

A total of 211 completed questionnaires were received from UK registered pharmacists; thus providing a response rate of $35.1 \%$ for this study. The participants included 102 females (48.3\%) and 103 males (48.8\%). With respect to age, the cohort were assigned to two brackets; namely between 2135 years old $(60.7 \%)$ and over 35 years old $(36.5 \%)$. Respondents were grouped as either 'pharmacy managers / owners' $(61.1 \%)$ or 'employee / locum / relief pharmacists' (36\%). In the main, pharmacy premises were linked to a regional or national chain $(60.2 \%)$ with others being members of local group or single independents 


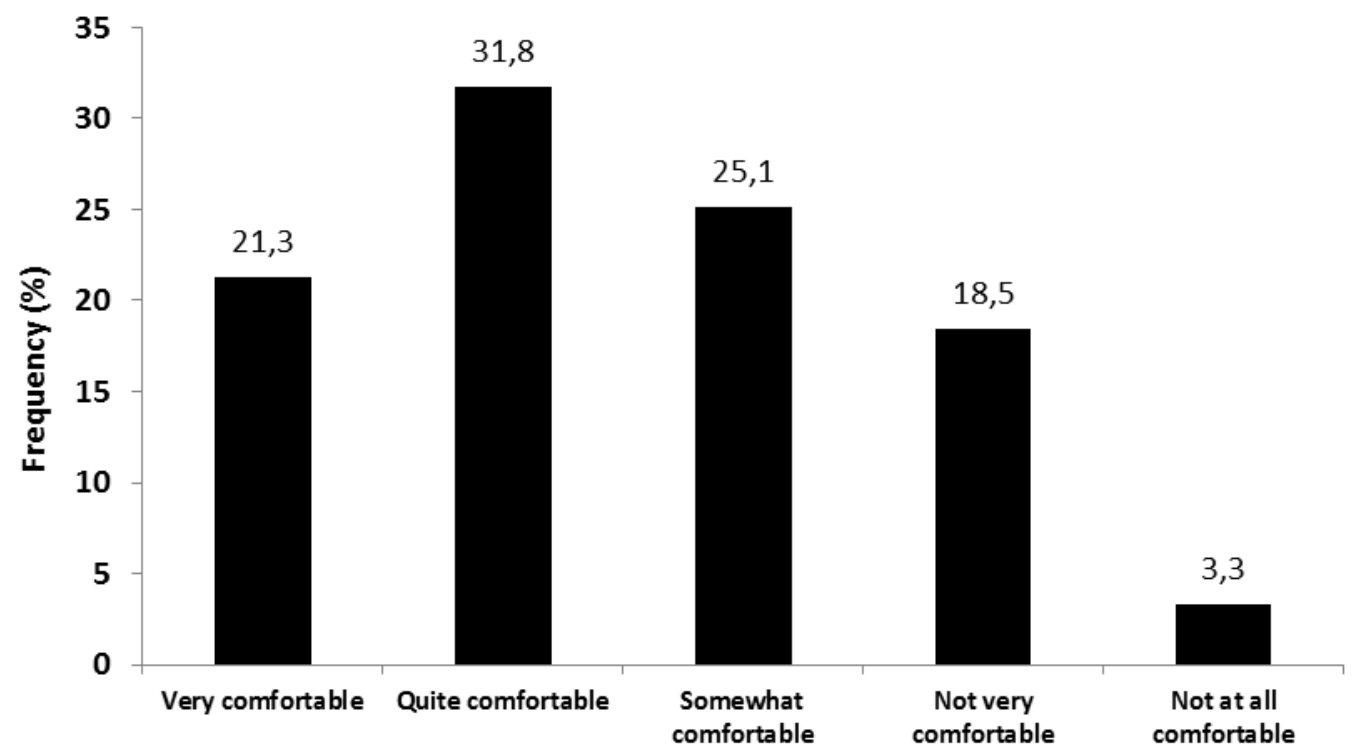

Figure 1. Pharmacist Level of Comfort with using a Mobile App over a Hard Copy Reference Source

(37\%). Participants possessed a wide ranging level of experience, with 119 people having practised for 10 years or less $(56.4 \%)$ and 86 participants working for 10 years or more $(40.8 \%)$. Within the study group 6 individuals failed to provide demographic information.

\section{Study Data}

\section{PHARMACISTS LEVEL OF CONFIDENCE AND COMFORT IN MOBILE APP USE}

The data suggest that those pharmacists surveyed were confident when using mobile apps on portable devices. The majority of respondents $(78.4 \%)$ agreed that they held a degree of confidence when using mobile apps, with only a small minority $(2.5 \%)$ of individuals stating that they were not at all confident. The trend in the data is to be expected as smartphone and tablet devices are now becoming engrained within society and it is expected that pharmacists would be use the technology on a daily basis.

Participants were subsequently invited to consider whether they would be comfortable in using a mobile app over a hard copy reference source, the results are presented in Figure 1.

In the main, respondents were comfortable in using mobile apps to acquire information located within traditional reference sources (i.e. BNF / Martindale). However, it was apparent that pharmacists demonstrated a degree of caution in this regard as illustrated by:

"It depends on the app; I would only use a referencing app if it were from an official source such as the BNF app." Pharmacist A.

"l'd only be happy to use and buy an application which was from an official body or organisation such as the BNF or NHS" Pharmacist B.
Furthermore with respect to daily practise, participants were asked to consider to what extent they agreed mobile apps have a role to play in providing advanced services to patients, the data are illustrated in Figure 2.

Upon inspection, it is evident that just over half of the respondents $(55 \%)$ agreed that mobile apps may offer potential to facilitate effective advanced service provision. However, a number of respondents suggested that the use of mobile apps may not be appropriate during patient consultations:

"If I have my phone out when talking to a patient, they often find it unprofessional" Pharmacist C.

"Older patients may find it rude if I use my phone during a consultation, l've had odd reactions before when simply using the calendar." Pharmacist D.

Overall, the data suggest that whilst the majority of pharmacists surveyed believe mobile apps may offer potential to aid patient consultations, care must be taken to ensure individuals are not offended when mobile technology is used during clinically important discussions.

\section{THE SUITABILITY OF MOBILE APPS IN HEALTHCARE EDUCATION}

Mobile apps may be employed within the healthcare setting to facilitate pharmacist, staff and patient education. Consideration was initially given to the suitability of mobile apps in pharmacist continuing education, the results are displayed in Figure 3.

Upon inspection, the majority of pharmacists $(80.5 \%)$ suggested that they would likely engage (i.e. very, quite or somewhat likely) with mobile apps to support their continuing education. Only a small minority of the sample (19.4\%) did not perceive mobile apps as useful tools to aid in the continuing education process. A number of supportive 


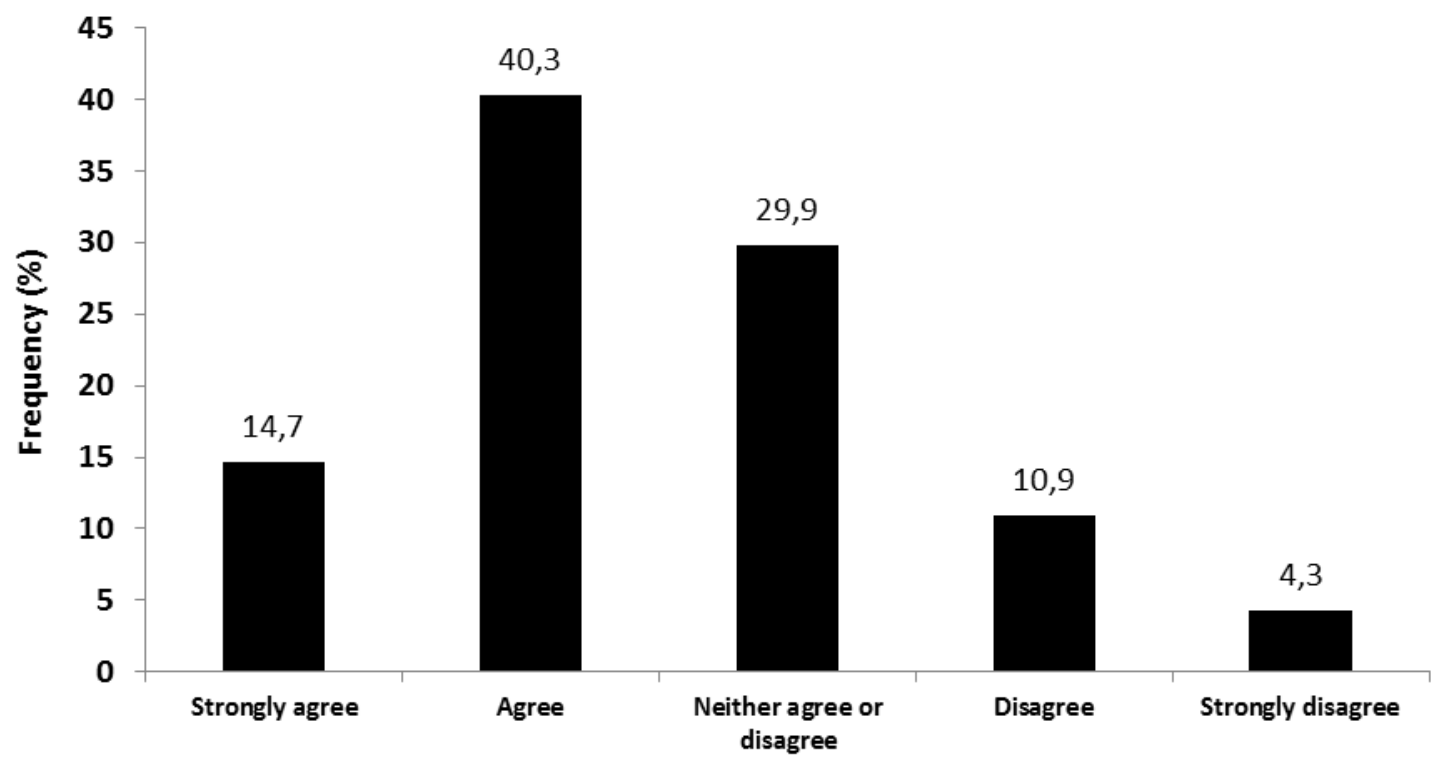

Figure 2. Mobile Apps Offer Scope to Aid the Pharmacist during Patient Consultations (i.e. MURs and NMS)

comments obtained from the pharmacists involved with the study included:

"I am seeing trends developing in the direction of apps for pharmacist's continuing education" Pharmacist E.

"Recording CPD on my phone would be very handy" Pharmacist F.

"I already use the CPPE monthly quiz app so I would be happy to use others." Pharmacist G.

With the use of mobile apps for staff training in mind, the respondents did in fact demonstrate a degree of comfort. Here, a total of $78.2 \%$ of those surveyed suggested that they were comfortable (i.e. very, quite or somewhat) in using mobile apps to facilitate staff training within the pharmacy. In a similar manner to the data presented above, a minority $(21.8 \%)$ were not fully comfortable in using the technology to assist with staff training.

In relation to these points, the respondents appeared to be relatively content in using mobile apps for patient education purposes. The majority of individuals $(80.1 \%)$ were generally (i.e. very, quite or somewhat) content with utilising mobile apps during periods of patient education; it was evident that $14.7 \%$ of individuals questioned were 'very content' to use mobile apps for this reason.

It is interesting to note the parallel within the data sets relating to pharmacist education, staff training and patient education. In all cases, the participants demonstrated a general agreement that mobile apps may indeed hold a role in the education of individuals within the modern day healthcare setting.

All participants were asked to consider whether they would or would not recommend a mobile app for a

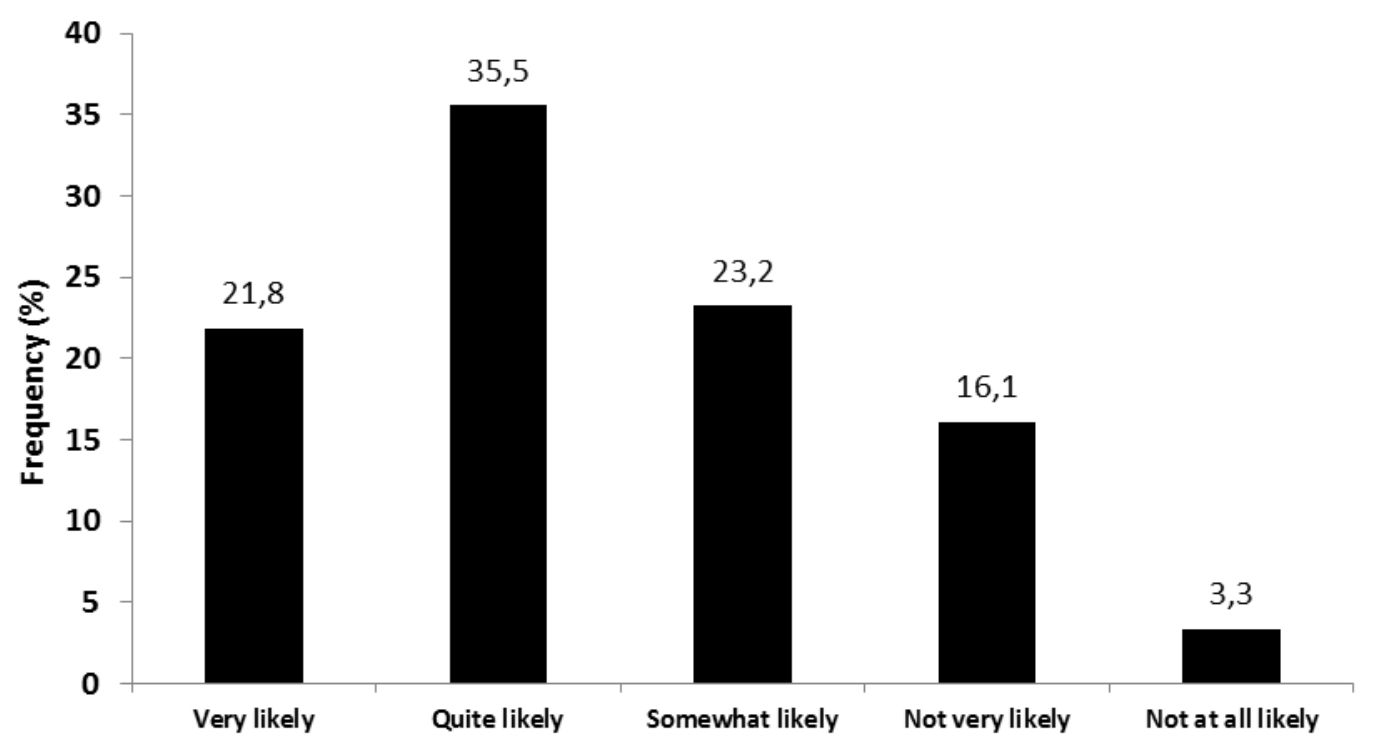

Figure 3. The Likelihood of Pharmacists using Mobile Apps for Continuing Education Purposes 


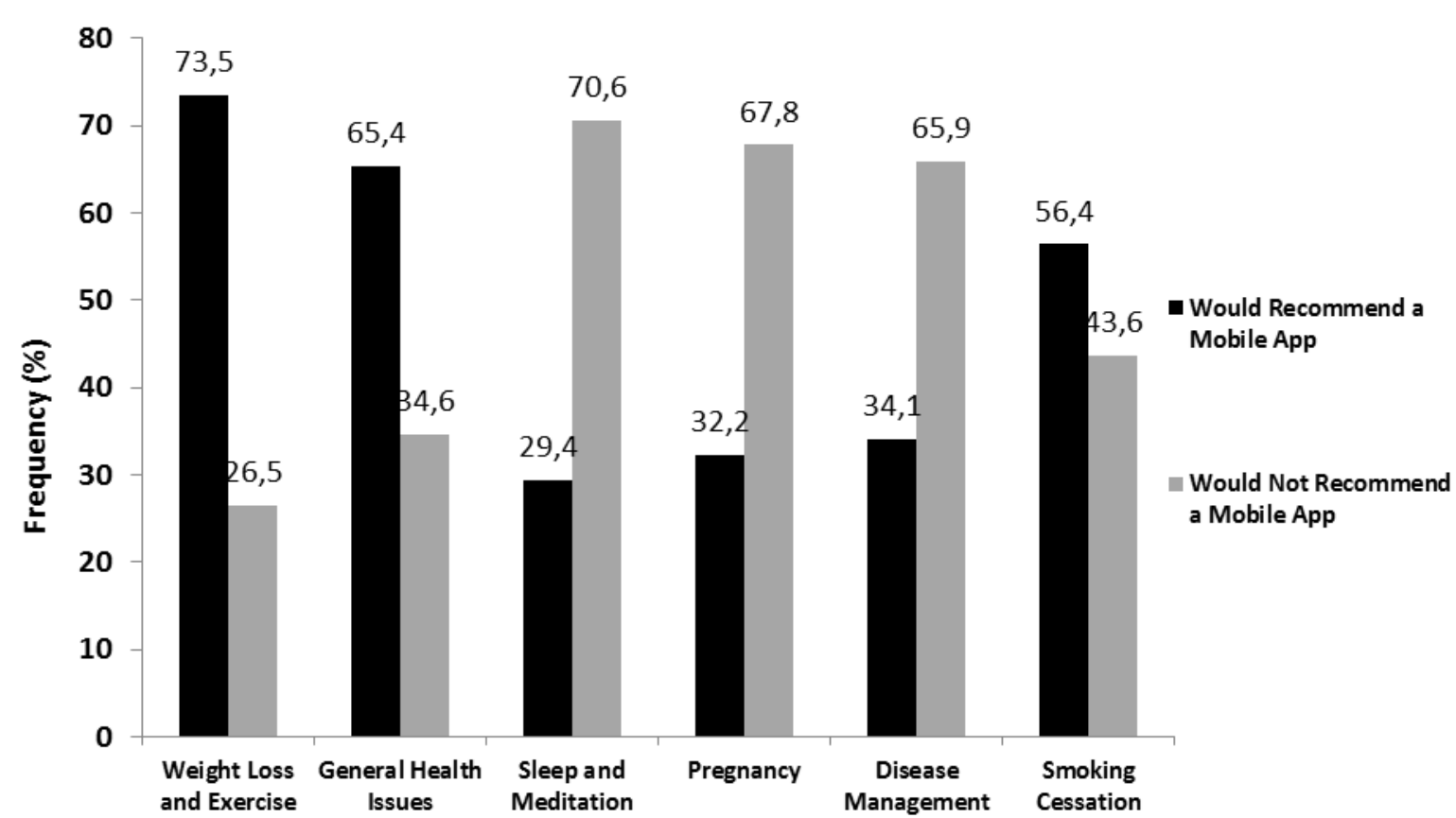

Figure 4. Pharmacist willingness to recommend a mobile app for a range of commonly presenting conditions

range of medical conditions that may present on a daily basis within the pharmacy; namely weight loss and exercise, general health issues, sleep and meditation, pregnancy, disease management and smoking cessation. The data acquired for this element of the study is presented within Figure 4.

The results indicate that the respondents would be more likely to recommend mobile apps to support weight loss $(73.5 \%)$, general health issues $(65.4 \%)$ and smoking cessation (56.4\%) within the community pharmacy setting. The participants appeared less willing to recommend mobile apps for sleep and meditation $(70.6 \%)$, pregnancy $(67.8 \%)$ and disease management $(65.9 \%)$. On reflection, a clear mismatch presents within the data set, which may be attributed to the level of risk perceived to both the pharmacist and the patient.

\section{BARRIERS TO MOBILE APP USE IN THE WORKPLACE}

Participants were invited to consider practical limitations to mobile app use within the community pharmacy setting; aspects for reflection included company policy, network coverage, battery life, time available for use and the cost of the mobile app. Here, the type of pharmacy was specifically considered. The data obtained from this arm of the study are presented in Table 1.

Upon inspection of the data, it is evident that all highlighted parameters impose some form of limitation on the use of mobile apps within the workplace. However, statistical significance was only apparent in the case of company policy $(p=0.000)$. It is apparent that pharmacists working within a regional or national chain were more likely to suggest that company policy would limit mobile app use when compared to counterparts employed within independent / local pharmacy outlets.

\section{THE ROLE OF MOBILE APPS IN MODERN DAY AND FUTURE PHARMACY PRACTISE}

The participants were finally asked to consider the role of mobile apps in both modern day pharmacy practise and the future of pharmacy practice. The data acquired from the element are illustrated in Figure 5.

Upon inspection of the data, it is evident that the bulk of pharmacists questioned $(75.9 \%)$ believed that mobile apps hold a role in modern day pharmacy practise (i.e. to a great, moderate or some extent). However, it is clear that most pharmacists $(89.6 \%)$ believed that mobile apps will be of great importance in the future (i.e. to a great, moderate or some extent). Overall, the views held by pharmacists regarding modern day use of mobile apps compared to future use of mobile apps were found to be significantly different $(p=0.000)$.

\section{DISCUSSION}

\section{Background}

Further to the implementation of the UK New Pharmacy Contract in 2005, community pharmacy

\begin{tabular}{|c|c|c|c|c|c|}
\hline \multirow{3}{*}{ Barrier } & \multicolumn{4}{|c|}{ Type of Pharmacy } & \multirow{3}{*}{ Significance Level } \\
\hline & \multicolumn{2}{|c|}{ Independent / Local Pharmacy } & \multicolumn{2}{|c|}{ Regional / National Chain } & \\
\hline & Yes & No & Yes & No & \\
\hline Company Policy & 33 & 45 & 94 & 33 & 0.000 \\
\hline Network Coverage & 31 & 47 & 62 & 65 & 0.206 \\
\hline Battery Life & 15 & 63 & 30 & 97 & 0.462 \\
\hline Time & 22 & 56 & 26 & 101 & 0.205 \\
\hline Cost of App & 14 & 64 & 46 & 81 & 0.005 \\
\hline
\end{tabular}




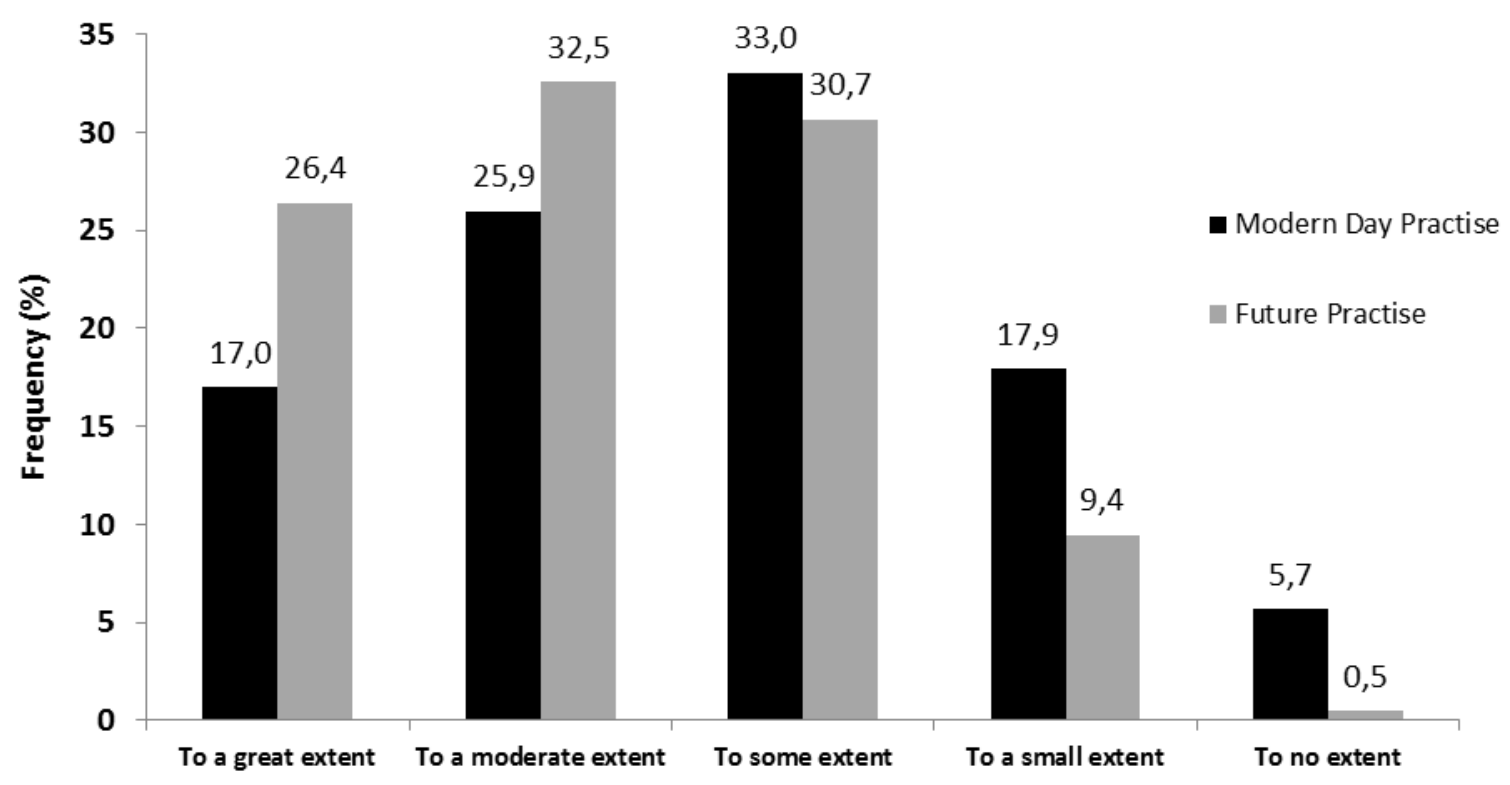

Figure 5. Pharmacist Opinion Regarding the Use of Mobile Apps in Modern Day and Future Practise

service models have changed significantly. Pharmacists practising within more developed countries (i.e. the UK and USA) now participate much more actively in delivering healthcare to the public. In a seemingly unrelated dimension, notable advances have been made within the field of mobile technology. The popularity of both smartphone and tablet devices has soared and as such this technology now appears to be feeding into modern day healthcare frameworks.

This preliminary study has considered the potential in combining these largely independent aspects in order to enhance the patient experience and health related outcomes within the community pharmacy setting. To date, limited research has been conducted to ascertain community pharmacist's perceptions relating to the use of mobile technology during service provision. With this technology market becoming an emerging force, exploration into the use of mobile apps in the field of pharmacy has never been more pertinent.

\section{Pharmacist Confidence with Mobile App Use}

In general, respondents indicated that they felt confident when using mobile apps. This finding may be ascribed to the way in which mobile devices have now become entrenched within society and the fact that it is highly likely that pharmacists would be proficient in using such platforms. Clearly, the level of confidence noted would enable the individual to derive maximum benefit from using a mobile app without it hindering daily workflow patterns. Here, the efficiency of use could facilitate decision making, aid in education and also expedite inter-individual communication, for example. With respect to those who did not express confidence when using mobile apps, opportunity exists to provide training (i.e. via workshops or tutorials) to improve understanding and competence, hence allowing for effective mobile app use in the workplace.

\section{Mobile Apps as Pharmacy Reference Sources}

The majority of participants were in favour of using mobile apps as reference sources. A number of reasons exist to explain this finding including for instance ready access to sources of information at the touch of a fingertip. A benefit such as this may lead to reduced waiting times and improvements in the patient counselling process. Arguably, one of the key advantages of using mobile apps in the healthcare setting is the capacity to rapidly access the most up-to-date medical information to assist in patient care. For instance, clinical guidelines (i.e. NICE guidance ${ }^{23}$ ) may be updated regularly but a pharmacist may not be able to directly access to the most up-to-date information due to the static nature of a hard copy source.

With the majority of approved healthcare organisations within the UK now offering access to mobile apps NHS staff / private contractors may have access to relevant, up-to-date information at the point of care. ${ }^{24}$ This arrangement may offer the potential for staff to roam freely within the workplace without the hindrance of having to carry a hard copy reference source(s).

Although the availability of clinical guidelines and medical information does appear favourable, understandably a number of respondents revealed concerns regarding the use of unregulated mobile apps during service provision. In this regard, it is a reasonable expectation that healthcare staff require such software platforms to be robust, reliable and safe; given the litigious nature of society. To ensure effective uptake and use of mobile apps in community pharmacy, certified apps from either accredited external organisations or indeed the employer should be devised and established.

\section{Mobile Apps and Patient Consultations}

Overall, respondents were not overwhelmingly in favour of using mobile apps during patient consultations, a result that may be attributed to the 
pharmacist perception of how the patient identifies with the consultation process as a whole. During a typical consultation, a pharmacist would engage with the patient and discuss medical information tailored specifically to that patient. Should a mobile app supported on a personal smartphone be used at this juncture, the patient may hold a negative view and perceive the technology platform as an obstacle to communication.

We therefore suggest that the type of mobile platform (i.e. smartphone or tablet device) used during patient consultations is pivotal for acceptance. Clearly, a company owned tablet device would enable the pharmacist to project a professional appearance whilst minimising any obstacles during the consultation process. This device type would be suitable because it would offer an interactive route by which to learn about disease and related management, it could allow ready visualisation of medicines use (i.e. correct inhaler technique) and could allow the pharmacist to update medical records at the touch of a button.

An excellent example of a recently released mobile app for use during patient consultations is the Boehringer Ingelheim software package called 'COPD Exchange', which may aid the community pharmacist during chronic obstructive pulmonary disease (COPD) consultations. ${ }^{25}$ It is approaches such as this that will enhance the patient experience within community pharmacy.

\section{Mobile Apps in Healthcare Education}

\section{PHARMACIST CONTINUING EDUCATION (CE)} AND STAFF TRAINING

Respondents suggested that they would engage with mobile apps to support their continuing education (CE) and staff training. Undoubtedly, mobile apps offer the pharmacist potential to conveniently engage with healthcare education and allow for ease of recording entries; points never more important with current workloads in mind. ${ }^{4}$ Overall, the use of such technology for CE purposes is fitting at this point in time as there is now increased emphasis placed on pharmacists to engage with lifelong learning and log the events on the General Pharmaceutical Council (GPhC) website, thus the easy access to such platforms would satisfy mandatory professional requirements. $^{12}$

However, perhaps one reason for the apparent reservation is the fact that pharmacists believe that CE would be best delivered by recognised or accredited training sessions and direct reference to the literature (i.e. journal articles). In this case, pharmacists may not consider mobile apps to be suitable for the sole purpose of $\mathrm{CE}$ and staff training. Indeed, we would fully support this view. Consequently, we suggest a balance be struck to enable effective use of mobile apps in lifelong learning or staff training. In this case, the pharmacist may attend training events and actively engage with training material, once complete mobile apps can be used consolidate taught material and record learning events. In the future we envisage mobile apps being routinely used to enhance pharmacists / staff learning experiences, and deepen levels of learners' engagement and collaboration within a digital learning environment. ${ }^{26}$

\section{PATIENT EDUCATION / SUPPORT}

Those pharmacists surveyed indicated that they would promote mobile apps for weight loss and exercise, general health issues along with smoking cessation. However, the categories of sleep and meditation, pregnancy and disease management garnered limited support. The trend in the data may be linked directly to the level of risk perceived by the pharmacist. Risk can be defined as exposing someone to possible harm. ${ }^{27}$ Arguably, the most important role of a pharmacist is to safeguard patients and hence minimise risk associated with treatment regimens (i.e. adverse drug reactions / interactions). ${ }^{28}$

The data suggest that pharmacists are more likely to recommend apps for 'low risk' conditions (i.e. smoking cessation) when compared to the more 'high risk' conditions (i.e. pregnancy). The results may be explained by the fact that mobile apps or alert mechanisms (i.e. SMS) for the more 'high risk' conditions hold potential to cause long term damage should they be incorrectly used or originate from an untrustworthy source. ${ }^{29}$ Pharmacists appear to be comfortable in recommending mobile apps for patients with conditions that do not have the potential of a sudden health decline. The finding aligns well with the work of Phipps and co-workers who consider the practice of pharmacy as 'sociotechnical' in nature, meaning that there are two sides to consider when considering risk in pharmacies (i.e. patient risk and the risk when providing pharmaceutical support). ${ }^{30}$ The group clarifies that incorporating risk assessment into pharmacy practice is vital and pharmacists must be fully aware of the repercussions of their actions (i.e. those actions associated with mobile app use). We would argue that regulation is central to mobile app uptake. Should a mobile app receive accreditation then the pharmacist will be safe in the knowledge that it is fit for purpose and would then be more likely to recommend it to manage a range of commonly occurring medical conditions, due to the reduction in risk.

In terms of patient support, mobile apps may enhance the provision of more advanced services such as MURs and also guide the patient with complex medication regimens. During patient consultations tablet devices, for example, could enable access to up-to-date medical records at the touch of a button and also present educational material (i.e. videos) relating to medicine use (i.e. correct inhaler technique) or the medical condition they have in an interactive manner. Indeed, a study conducted by Strayer and co-workers in 2010 demonstrated that patients were mainly in favour of the use of tablet devices and related content during consultations with prescribers. ${ }^{31}$

In addition, apps may hold value in reminding the patient when to take their medication. In the UK hundreds of millions of pounds are lost each year as a result of medication wastage; a large proportion of 
this loss may be linked to patient non-compliance. ${ }^{32}$ Furthermore, it is estimated that a total of 7 million people missed scheduled hospital appointments, causing delayed treatment time to other patients and costing the National Health Service (NHS) millions of pounds. Clearly patient reminders sent via mobile apps present as an ideal route to minimise issues such as these. ${ }^{33}$ Indeed, programmes such as the Managed Appointment Reminder Service (MARS) aim to reduce the financial loss reported by the NHS. This particular service has successfully been piloted in The Hull and East Yorkshire Hospital. ${ }^{34}$

\section{Barriers to Mobile Apps in the Workplace}

Respondents suggested that a number of issues (i.e. network coverage and battery life) restricted the use of mobile apps within the workplace. The data clearly indicate that company policy was the major limitation to mobile app use, which may be linked directly to the employer viewing mobile devices as distracting for the pharmacist. ${ }^{35,36}$ Also, it is evident that the type of pharmacy in which a pharmacist practises holds a large impact on this element. For instance those individuals who work within independent / small local group pharmacy perceive the issue to be a minor problem, with the opposite true for counterparts employed in regional / national chains. Consequently, it is feasible to propose that if such policies remain mobile apps will have a limited role in the provision of healthcare to the public in the future. ${ }^{20}$ In order to circumvent this issue, we propose mobile device management strategies should be implemented. ${ }^{37}$ Irrespective of the format of the pharmacy, all premises must be viewed as retail businesses that provide a clinically relevant, professional service. ${ }^{4}$ To this end, the uptake of mobile apps within the community pharmacy setting would require thorough planning and evaluation. Here, we envisage the tailoring of mobile apps to the specific organisation(s) being the way forward to improving general acceptance. ${ }^{7,38}$

\section{The Suitability of Mobile App use in Modern and} Future Practise

Those pharmacists surveyed hold value in the use of mobile apps for both modern day practice and particularly future practice. It is interesting to consider, at this juncture, the UK population demographic and how may influence mobile app use within the community setting. The UK currently has an ageing population, with the number of elderly people set to double from 10 to 20 million by 2050 . $^{39}$ At this point in time, the relatively large number of individuals described as the 'older generation' would be either unable or unwilling to use mobile apps to support their health needs. ${ }^{20}$ However, the current 'younger generation' is much more likely to embrace the use of mobile apps in healthcare plans because they are accustomed to such technology. Over the course of time as the younger generation ages and naturally 'replaces' the current older generation, the use of apps as part of a treatment plan is much more likely to become prevalent. It is conceivable, therefore, that mobile apps may hold a central position in the future delivery

\section{CONCLUSIONS}

In general, those pharmacists surveyed were in favour of mobile app use within the community setting. Although the participants expressed comfort in using mobile apps, several concerns were declared. Pharmacists alluded to the fact that mobile apps must be accredited to ensure the information provided is accurate and trustworthy. Concern was aired regarding the suitability of use of a mobile device during patient consultations. Company policy, as it stands at the moment, may indeed be a major stumbling block for the use of this technology. Undoubtedly, drawbacks such as these must be addressed to ensure effective uptake of mobile apps in supporting patient care.

We recommend further work be performed to better understand this field. To this end, it would be beneficial to probe the opinions held by both the public and service providers. To enable effective roll out, it is important to ensure that all parties involved with such technology are content. If a deeper understanding of current opinion surrounding the use of mobile apps in the community pharmacy is gained, scope exists to develop the technology accordingly and thus provide a promising new route by which to provide pharmaceutical care within the community setting.

\section{ACKNOWLEDGEMENTS}

The authors would like to express their gratitude to all participants who took part in this study. Our special thanks go to Dr Phil Rowe for support during statistical analysis and LJMU for funding this research effort.

\section{CONFLICT OF INTEREST}

None declared.

\section{APPS DE FARMACIA: UNA NUEVA FRONTERA EN EL PAISAJE DIGITAL?}

\section{RESUMEN}

Antecedentes: La tecnología de smatphones y tablets ha evolucionado rápidamente en el transcurso de los últimos años. Igualmente, la esfera de la sanidad está constantemente en desarrollo y esforzándose para incluir las nuevas formas de la tecnología para optimizar su funcionamiento. Están apareciendo muchas oportunidades para las aplicaciones de móviles (i.e., 'apps') en el sector de la salud.

Objetivo: este estudio considera si los farmacéuticos registrados en el Reino Unido (UK) creen apropiado el uso de apps de móviles durante la atención a la salud en el entorno comunitario.

Métodos: Después de la aprobación de ética de la Liverpool John Moores University (LJMU), el cuestionario de 30 ítems fue distribuido a los farmacéuticos registrados en UK que trabajaban en la ciudad de Manchester, Liverpool and Newcastle $(n=600)$. Se formatearon las preguntas como escalas de Likert de selección múltiple o de tipo abierto. Cuando completaron y devolvieron los cuestionarios, se analizaron los datos usando frecuencias simples, tablas de contingencia y métodos no paramétricos en el SPSS (v18). 
Resultados: La mayoría de los respondentes $(78,4 \%$ de 211 participantes) confirmaron que sentían confianza cuando usaban apps de móviles en sus plataformas tecnológicas. En general, las apps de móviles eran percibidas como útiles para facilitar la consulta con el paciente $(55 \%)$ y apoyar la educación sanitaria $(80 \%)$. La principal barrera para el uso de apps de móviles en el lugar de trabajo era la política de la compañía, lo que resultó significativo en el caso de cadenas de farmacias regionales / nacionales $(p<0,001)$. Los farmacéutico aludieron al hecho de aunque las apps de móviles demuestran un potencial en la práctica diaria moderna, tendrán mayor impacto en el futuro $(\mathrm{p}<0,001)$.

Conclusión: Los datos indican que aunque los farmacéuticos son favorables a las apps de móviles en la atención sanitaria, determinados factores (i.e., riesgo, política de compañía y falta de reglamentación) pueden impedir su uso en la práctica diaria moderna. Claramente, deben afrontarse las limitaciones de la tecnología para maximizar su beneficio en los sistemas sanitarios. Los farmacéuticos sugieren que, a medida que las generaciones más jóvenes crezcan, las aplicaciones de móviles serán un método más aceptado para la atención sanitaria en mayores poblaciones.

Palabras clave: Teléfono Móvil; Ordenadores de Bolsillo; Farmacéuticos; Práctica Profesional; Reino Unido

\section{References}

1. Konschak C, Davaloor R. Mobile Applications in Healthcare. White Paper. 2011;(1):1-5

2. The UK Mobile Phone Blog. How Many Apps for Smartphones in 2012. http://blog.mobiles.co.uk/app-reviews/howmany-apps-2012/ (Accessed 12th October 2012).

3. Aleksey Sukhanov. What is an App? http://ipad-applications.neiia.com/article/222/what-is-an-app/ (Accessed 18th October 2012).

4. Davies MJ, Fleming H, Jones R, Menzie K, Smallwood C, Surendar S. The inclusion of a business management module within the master of pharmacy degree: a route to asset enrichment? Pharm Pract (Granada). 2013;11(2):109-117.

5. Department of Health. Maps and Apps. http://mapsandapps.dh.gov.uk/2012/03/02/video-andrew-lansley-speaks-at-themaps-and-apps-showcase-event/ (Accessed 17th October 2012).

6. BNF 63: British National Formulary 63. London: British Medical Association \& Royal Pharmaceutical Society of Great Britain; 2012.

7. DeArment A. Tablets, Mobile Apps Transform Pharmacy. Drug Store News. 2011;33(16):38.

8. Wangberg SC, Arsand E, Andersson N. Diabetes Education via Mobile Text Messaging. J Telemed Telecare. 2006;12(Suppl 1):55-56.

9. Cai YY, Cao D, He XH. Wang QX. Continuous Glucose Monitoring System Based on Smart Phone. Procedia Eng. 2012;29:3894-3898. doi: 10.1016/j.proeng.2012.01.590

10. Kim B. Ball M. Mobile Use in Medicine: Taking a Cue from Specialized Resources and Devices. The Reference Librarian. 2010; 52: 57-67. doi: 10.1080/02763877.2011.521733

11. General Pharmaceutical Council (GPhC): http://www.uptodate.org.uk/PlanandRecord/version4/PlanandRecordVersion14CompleteGuidancePack.pdf (Accessed 18th October 2012).

12. General Pharmaceutical Council (GPhC): http://pharmacyregulation.org/ (Accessed 18th October 2012).

13. James D. Addressing the Continuing Professional Development Needs of Community Pharmacists. Pan Thames Conference Abstracts. 2002;13:189-205

14. Rouse MJ. Continuing Professional Development in Pharmacy. Am J Health Syst Pharm. 2004;61(19):2069-2076

15. Learning and development: http://www.bootsuk.com/Corporate Social Responsibility/Workplace/Training and development.aspx (Accessed 6th February 2013).

16. Haffey F, Brady RR, Maxwell S. Smartphone apps to support hospital prescribing and pharmacology education: a review of current provision. Br J Clin Pharmacol. 2014;77(1):31-38. doi: 10.1111/bcp.12112

17. Centre for Pharmacy Postgraduate Education (CPPE). Useful Apps for Pharmacy: http://www.cppe.ac.uk/News/Article.asp?articlelD=290\&ID=78 (Accessed 6th February 2013)

18. Brock TP, Smith SR. Using digital videos displayed on personal digital assistants (PDAs) to enhance patient education in clinical settings. Int J Med Inform. 2007;76(11-12):829-835.

19. Dayer L, Heldenbrand S, Anderson P, Gubbins PO, Martin BC. Smartphone medication adherence apps: potentia benefits to patients and providers. J Am Pharm Assoc (2003). 2013;53(2):172-181. doi: 10.1331/JAPhA.2013.12202

20. Hersh W. Health care information technology: progress and barriers. JAMA. 2004;292(18):2273-2274.

21. Smith JS. Jones RP. Medical Applications: The Future of Regulation. Bull R College Surg Engl. 2012;94(1):12-13.

22. Aungst TD. Medical applications for pharmacists using mobile devices. Ann Pharmacother. 2013;47(7-8):1088-1095. doi: 10.1345/aph.1S035

23. National Institute for Health and Clinical Excellence (NICE): http://guidance.nice.org.uk/ (Accessed 6th February 2013)

24. E-Health. NICE launches BNF smartphone app: http://www.ehi.co.uk/news/ehi/7824/nice-launches-bnf-smartphone-app (Accessed 16th February 2013).

25. PM Group Worldwide Ltd. Boehringer Launches COPD Patient Consultation App for HCPs. http://www.pmlive.com/blogs/digital intelligence/archive/2013/january/boehringer launches copd patient consultation app for hcps (Accessed 20th March 2013).

26. BMC Medical Education. Wikis, Blogs and Podcasts: A New Generation of Web-based Tools for Virtual Collaborative Clinical Practice and Education: http://www.biomedcentral.com/1472-6920/6/41 (Accessed 20th March 2013). 
27. Oxford Dictionaries. Risk. http://oxforddictionaries.com/definition/english/risk (Accessed 1st March 2013).

28. Prospects. Community pharmacist: Job description: http://www.prospects.ac.uk/community pharmacist job description.htm (Accessed 1st March 2013).

29. Obermayer JL, Riley WT, Asif O, Jean-Mary J. College Smoking Cessation using Cell Phone Messaging. J Am Coll Health. 2004;53(2):71-78.

30. Phipps DL, Noyce PR, Walshe K, Parker D. Ashcroft DM. Risk-based Regulation of Healthcare Professionals: What are the Implications for Pharmacists? J Health Risk Soc. 2011;13(3):277-292. doi: 10.1080/13698575.2011.558624

31. Strayer SM, Semler MW, Kington ML, Tanabe KO. Attitudes Toward Physician Use of Tablets in the Exam Room. Fam Med. 2010;42(9):643-647.

32. National Health Service. The Pharmaceutical Services (Advanced and Enhanced) (England) Directions 2012. http://www.dh.gov.uk/health/files/2012/07/The-Pharm-Services-Advanced-Enhanced-Services-Directions-2012.pdf (Accessed 19th October 2012).

33. NHS Commercial Solutions. Cost of Missed Appointments: http://www.commercialsolutionssec.nhs.uk/newspage.php?pid=1239 (Accessed 14th February 2013).

34. Deadline. NHS prescribes $£ 22,500$ worth of iPad: http://www.deadlinenews.co.uk/2012/05/25/nhs-prescribes-22500worth-of-ipad/ (Accessed 1st March 2013).

35. Venta L, Isomursu M, Ahtinen A. Ramiah S. My Phone is part of my soul - how people bond with their mobile phones. Proc UbiComm. 08. IEEE Computer Society. 2008: 311-317. doi: 10.1109/UBICOMM.2008.48

36. Siska $\mathrm{MH}$, Tribble DA. Opportunities and challenges related to technology in supporting optimal pharmacy practice models in hospitals and health systems. Am J Health Syst Pharm. 2011;68(12):1116-1126. doi: 10.2146/ajhp110059

37. Gebauer H. Robust management policies for positioning pharmacies as healthcare service providers. Eur Manag J. 2008;26(3):175-187. doi: 10.1016/j.emj.2008.01.003

38. Lasky T, Kogut S, Campbell S. Risica PM. Computer Kiosks to Deliver Medication Information in the Pharmacy. J Consum Health Internet. 2011;15(4):347-360. doi: 10.1080/15398285.2011.623579

39. Parliament. The Ageing Population: http://www.parliament.uk/business/publications/research/key-issues-for-the-newparliament/value-for-money-in-public-services/the-ageing-population/ (Accessed 1st March 2013). 